\title{
Morphological variation in leatherback (Dermochelys coriacea) hatchlings at Sandy Point National Wildlife Refuge, US Virgin Islands
}

\author{
Shreya M. Banerjee ${ }^{1,6, *}$, Amy Frey ${ }^{2}$, Carolyn M. Kurle ${ }^{3}$, Justin R. Perrault ${ }^{4,7}$, \\ Kelly R. Stewart ${ }^{5}$ \\ ${ }^{1}$ Scripps Institution of Oceanography, University of California, San Diego, La Jolla, CA 92037, USA, \\ ORCID: 0000-0003-1210-2162 \\ ${ }^{2}$ Marine Mammal and Turtle Division, Southwest Fisheries Science Center, National Marine Fisheries Service, \\ National Oceanic and Atmospheric Administration, La Jolla, CA 92037, USA \\ ${ }^{3}$ Division of Biological Sciences, Ecology, Behavior, and Evolution Section, University of California, San Diego, La Jolla, \\ CA 92093, USA, ORCID: 0000-0003-1121-9924 \\ ${ }^{4}$ Department of Biological Sciences, Florida Atlantic University, Boca Raton, FL 33431, USA \\ ${ }^{5}$ The Ocean Foundation, Washington, DC 20036, USA, ORCID: 0000-0002-8673-5192 \\ ${ }^{6}$ Present address: Department of Biology, Stanford University, Stanford, CA 94305, USA \\ ${ }^{7}$ Present address: Loggerhead Marinelife Center, Juno Beach, FL 33408, USA, ORCID: 0000-0002-5046-6701
}

\begin{abstract}
Understanding species' mating systems provides important information about their ecology, life history, and behavior. Direct observations of mating behaviors can be challenging, but molecular techniques can reveal information about mating systems and paternal identity in difficult-to-observe species such as sea turtles. Genetic markers can be used to assess the paternity of a clutch and to assign hatchlings to a father. Leatherback turtles Dermochelys coriacea sometimes mate with multiple individuals, resulting in clutches with mixed paternity; however, the effects of multiple paternity on hatchling quality are unclear. Leatherback hatchlings at Sandy Point National Wildlife Refuge, St. Croix, US Virgin Islands, exhibit visible variation in individual body size, sometimes within the same clutch. We collected morphometrics and tissue samples from hatchlings across multiple nesting seasons $(2009,2012,2013,2015$, and 2016) and found that hatchlings exhibited small but statistically significant differences in morphometrics between years. We used maternal and hatchling microsatellite genotypes to reconstruct paternal genotypes, assigning fathers to each hatchling. We found multiple paternity in 5 of 17 clutches analyzed and compared differences in morphometrics between full-siblings with differences between half-siblings. We found no significant differences between morphometrics of hatchlings from the same mother but different fathers. We compared within-clutch variances in morphometrics for clutches with and without multiple paternity and found no significant difference in morphological variation between them. Therefore, we could not attribute differences in hatchling size within a clutch to paternal contribution. Understanding other factors affecting hatchling morphology, and other possible fitness metrics, may reveal insights into the benefits, or lack thereof, of polyandry in sea turtles.
\end{abstract}

KEY WORDS: Paternal contribution $\cdot$ Hatchling morphology $\cdot$ Multiple paternity $\cdot$ Microsatellites Sea turtle 


\section{INTRODUCTION}

Investigating relationships between paternity and offspring fitness can be challenging, as both measurements of fitness and direct observations of paternity can be difficult to obtain in species where individuals are not easily observed in the wild. However, molecular techniques can provide insights into paternity and mating systems of hard-to-observe species (Lee 2008). These types of data indicate that multiple paternity is a common phenomenon across many taxa and is found in $50 \%$ of non-avian reptile clutches (Uller \& Olsson 2008). The prevalence of multiple paternity has led to several studies linking offspring characteristics (e.g. body size, survivorship, genetic diversity) to multiple paternity and paternal identity (Kempenaers et al. 1997, Lee \& Hays 2004, Thonhauser et al. 2014). It has also been hypothesized that females mate with multiple males to increase genetic diversity in their offspring or to recover potentially lost fitness from mating with a low-quality male (Pearse \& Avise 2001, Stewart \& Dutton 2014). Indeed, some data show positive correlations between multiple paternity and traits used to determine fitness, such as chick survivorship in blue tits Parus carrulus (Kempenaers et al. 1997) and clutch size in painted turtles Chrysemys picta (Pearse et al. 2002), but there has been little evidence for direct or indirect fitness advantages from multiple paternity in marine turtle species (Lee et al. 2018).

Body size is a trait commonly used to assess the quality of offspring because it is easily measured in multiple species. Some evidence supports the 'bigger is better' hypothesis, which suggests that larger offspring have an increased chance of survival and reproduction (Bobyn \& Brooks 1994, Janzen et al. 2000, 2007, McMahon et al. 2000, Cornioley et al. 2017). For example, larger southern elephant seal Mirounga leonina pups are more likely to survive their first year than smaller individuals (McMahon et al. 2000). Similarly, red-eared slider Trachemys scripta elegans hatchlings with larger body size have higher recapture rates, indicating lower mortality rates (Janzen et al. 2000, 2007). Hatchling body size was also found to be positively correlated with survival in snapping turtles Chelydra serpentina, although this correlation was only evident when comparing hatchlings from different mothers (Bobyn \& Brooks 1994). Therefore, offspring body size influences survival in some species and may be a practical proxy for fitness. Body size can also be influenced by paternal identity. For example, in wandering albatrosses Diomedea exulans, fathers with larger body mass produce larger chicks, which then have higher survival rates than those from smaller fathers (Cornioley et al. 2017).

Molecular techniques are useful for inferring the mating behavior of marine species, which are difficult to observe in the open ocean (Stewart \& Dutton 2014, Komoroske et al. 2017). One such molecular technique is microsatellite analysis, which allows us to differentiate even closely related individuals by the fragment length of repetitive sections of non-coding DNA. Microsatellite analysis has revealed multiple paternity as a result of females mating with more than one male in the same reproductive season in green turtles Chelonia mydas (Ireland et al. 2003, Alfaro-Núñez et al. 2015, Chassin-Noria et al. 2017, Joseph et al. 2017), olive ridleys Lepidochelys olivacea (Jensen et al. 2006, Duran et al. 2015), Kemp's ridleys L. kempii (Kichler et al. 1999, Frey et al. 2014), hawksbills Eretmochelys imbricata (Phillips et al. 2013, GonzálezGarza et al. 2015), flatbacks Natator depressus (Theissinger et al. 2009), loggerheads Caretta caretta (Moore \& Ball 2002, Tedeschi et al. 2014), and leatherbacks Dermochelys coriacea (Crim et al. 2002, Stewart \& Dutton 2011). Stewart \& Dutton (2011, 2014) used paternity analysis to reconstruct paternal genotypes from maternal and hatchling genotypes to determine annual adult breeding sex ratios for the St. Croix, US Virgin Islands nesting population of leatherbacks. Using molecular techniques to identify male contribution is critical because sea turtles are often difficult to capture in the open ocean, and observations of mating are particularly rare in leatherbacks, so most assessments are made from nesting females (Carr \& Carr 1986, James et al. 2005). Understanding male contribution to mating systems of marine turtles is critical for determining demographic indices such as population growth and for predicting future population trends (Komoroske et al. 2017).

Leatherback hatchlings exhibit phenotypic variation in morphological traits that may be due to environmental factors, maternal investment, or genetic factors (Wallace at al. 2006, 2007). For example, differences in mass ranged from 0.2 to $6.4 \mathrm{~g}(0.5$ to $16.0 \%$ of the population mean) in leatherback hatchlings from the same female at Parque Nacional Marino Las Baulas, Costa Rica (Wallace et al. 2007). Hatchling size was found to be positively correlated with egg mass in smooth softshell turtles Apalone mutica (Janzen 1993), and negatively correlated with incubation temperature in all species of sea turtles (Booth \& Astill 2001); a combination of maternal and genetic components is thought to drive this size variation. Other studies found a $2 \mathrm{~g}$ increase in hatchling mass for every $10 \mathrm{~g}$ increase in egg mass for leatherbacks and 
suggested that variation in the characteristics of hatchlings was due to interactions between the environment and genetic input from one or both parents (Wallace et al. 2006, 2007). If environmental conditions are the primary drivers of leatherback hatchling morphological variation at Sandy Point National Wildlife Refuge (SPNWR), we would expect to see differences in morphometrics between years, as environmental conditions such as rainfall and beach erosion are variable between years. However, if genetic input from one or both parents are the primary drivers for hatchling morphological variation, we would expect to see no differences in morphometrics between years because leatherbacks return to the same breeding and nesting regions throughout their lives, although this may be confounded by multi-year remigration intervals (McDonald \& Dutton 1996).

In this study, we addressed the following objectives: (1) What is the variation in morphology for leatherback hatchlings at SPNWR, and does it vary by year? (2) Is morphological variation within a clutch of leatherback sea turtle hatchlings in multiple paternity clutches related to paternal identity? (3) Do clutches with multiple paternity have greater morphological variation among hatchlings? If hatchling body size is related to paternal identity, we would expect to detect differences in morphometrics between hatchlings with different fathers from the same clutch. We would also expect to see greater morphological variation in multiple paternity clutches, which

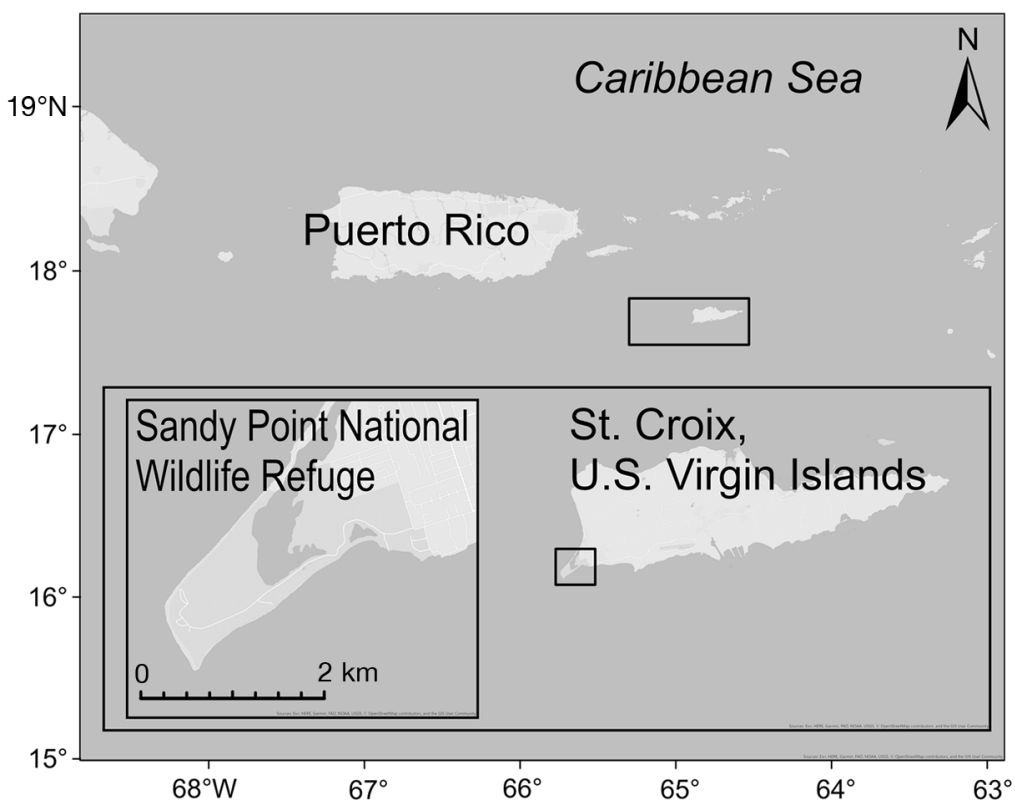

Fig. 1. Sandy Point National Wildlife Refuge, on the southwestern edge of St. Croix, US Virgin Islands inherently have greater allelic diversity from more contributing parents. To assess these hypotheses, we (1) characterized body size in leatherback hatchlings and (2) used microsatellite analysis to better understand potential paternal contribution to hatchling body size and the relationship between multiple paternity and body size variation. The answers to these questions further our understanding of factors that affect hatchling morphology and demonstrate the utility of reconstructing paternal genotypes using microsatellite markers.

\section{MATERIALS AND METHODS}

\subsection{Field site}

We conducted fieldwork at SPNWR, a beach on a small peninsula at the southwestern end of St. Croix, US Virgin Islands. SPNWR (Fig. 1) supports a nesting population of Atlantic leatherbacks that has been studied for several decades (Dutton et al. 1999, 2005, Roden \& Dutton 2011, Stewart \& Dutton 2014, Garner et al. 2017). The beach has been under federal protection since 1984 when it became a refuge and subsequently saw an increase in the leatherback nesting population until the early 2010s (Dutton et al. 2005, Garner et al. 2017). Females at SPNWR nest from March through July, and nests hatch from May through August. The number of nests laid annually on SPNWR between 1982 and 2010 ranged from 72 to 988 (Garner et al. 2017). The maternal identities for all clutches laid on this beach are very reliable, as all females are identified through passive integrated transponder (PIT) tags, flipper tags, and genetic analysis. Clutch locations for each observed clutch are also recorded. We collected morphometrics and/or tissue samples from hatchlings that were from the first emergence from these nests. Data used in this study were collected over 5 seasons between 2009 and 2016; a summary of data collection and associated objectives may be found in Table $\mathrm{S} 1$ in the Supplement at www.int-res.com/articles/ suppl/n041p361_supp.pdf.

\subsection{Morphology measurements}

We collected morphology measurements from hatchlings during 5 nesting seasons (2009, 2012, 2013, 2015, 2016). We measured 
mass (g) with a Pesola $100 \mathrm{~g}$ spring scale (model no. 10100), straight carapace length (SCL, mm), straight carapace width (SCW, $\mathrm{mm})$, and body depth (BD, $\mathrm{mm}$ ) using vernier calipers (SPI no. 6056449). We calculated body condition index $(\mathrm{BCI})$ as $\left(\operatorname{mass} / \mathrm{SCL}^{3}\right) \times$ 10000 for each hatchling (Bjorndal \& Bolten 2000, Labrada-Martagon et al. 2010).

\subsection{Genetic sampling}

We collected hatchlings from nests with known mothers and took skin samples from the trailing edge of the front flipper using a $2 \mathrm{~mm}$ biopsy punch as described in Dutton \& Stewart (2013). We applied styptic pencil (aluminum sulfate $56 \%$ ) to each biopsy site to prevent bleeding and released all hatchlings within $2 \mathrm{~h}$ of collection (Dutton \& Stewart 2013). We stored skin samples individually in a saturated salt $(\mathrm{NaCl})$ solution in 96 well Sorensen PCR plates. We recorded each hatchling's sample location in the 96 well plate along with its paired morphology measurements when paired measurements were available. Genetic samples from known mothers were collected previously (Stewart \& Dutton 2014). We kept samples in a $-20^{\circ} \mathrm{C}$ freezer in the Southwest Fisheries Science Center in La Jolla, CA, prior to analysis.

\subsection{DNA analysis}

We genotyped each nesting female and 12 to 24 of her hatchlings per clutch. A manual salt extraction (Hillis \& Davis 1986, Dutton et al. 1999) was used to isolate DNA from the hatchling and nesting female tissue samples including negative control extractions (without tissue) in each extraction batch to ensure that the DNA extractions were not contaminated. The DNA was quantified using a Nanodrop Spectrometer or a Victor Fluorometer and then diluted to $4 \mathrm{ng} \mathrm{l}^{-1}$ with Milli-Q water. For each sample, the DNA was amplified in PCR for 4 microsatellite markers, DERM01, DERM02, DERM37, and DERM48 (Alstad et al. 2011) in $25 \mu \mathrm{l}$ reactions in a Thermal Cycler 2720 (PE Applied Biosystems) at temperatures and run times specific to those markers. The additional markers LB142 (Roden \& Dutton 2011), Cc5C08t, and Cc5H07t (Shamblin et al. 2007) were used for a few clutches for which the DERM primers did not amplify well. We performed PCR reactions for each of these primers without DNA (negatives) as controls to check for contamination between samples. We determined the genotypes of each sample at each marker using an ABI Prism 3730 genetic analyzer with ROX500 fluorescent size standard (Applied Biosystems), scored alleles using GeneMapper v.5.0 (Applied Biosystems), and manually verified each allele call. We replicated 51 sample genotypes to assess genotyping error rate. We classified hatchling genotypes without a maternal allele as a genotyping error. In this study, we also used genetic data from 10 clutches laid in 2009, previously analyzed with similar methods and published in Stewart \& Dutton (2011).

Allele frequencies were calculated from 30 nesting females (known mothers) genotyped in this study to assess Hardy-Weinberg equilibrium and heterozygosity for each of the polymorphic loci using the program GENEPOP (Raymond \& Rousset 1995, Rousset 2008). The probability of detecting multiple paternity $(D)$ was also calculated from the allele frequencies of 30 nesting females with the formula given in Westneat et al. (1987). Additionally, we used the formula given in Hanotte et al. (1991) to calculate the probability that 2 unrelated individuals shared the same multi-loci genotype due to chance $(Q)$ from the allele frequencies of 30 nesting females. We also used the R package 'PopGenReport' (Adamack \& Gruber 2014) to calculate the frequency of null alleles for each locus with the method described in Chakraborty et al. (1994). Locus statistics for the 10 clutches from 2009 are reported in the study for which they were originally analyzed (Stewart \& Dutton 2011).

\subsection{Multiple paternity analysis}

We found that the St. Croix nesting population of leatherbacks had 8 or more alleles at each of the genetic markers we used, so we were able to use these markers to differentiate individuals and assign parents to hatchlings within this nesting population. We determined paternal alleles for at least 4 loci in each of the hatchlings by comparing each hatchling genotype to that of its mother for each clutch analyzed. All hatchlings should have at least one maternal allele, so hatchlings without a maternal allele were not the mother's offspring, had a mutation, or were incorrectly genotyped. We considered clutches with more than 2 paternal alleles per locus, for at least 2 loci, as confirmed cases of multiple paternity (Stewart \& Dutton 2011). The computer program GERUD 1.0 was used to confirm paternal alleles and reconstruct paternal genotypes based on paternal alleles paired with each other at multiple loci (Jones 2001). All paternal genotypes used to assign hatch- 
lings to a father in this study were fully resolved with the program GERUD 1.0.

We assigned each hatchling in the clutches with multiple paternity and paired genetic and morphological data to its father. We identified each hatchling's paternal alleles by excluding maternal alleles and used each hatchling's paternal alleles to assign it to a father. This was done at multiple loci to confirm paternity. We excluded from further analysis those hatchlings for which we could not clearly determine paternity.

\subsection{Statistical analyses}

Hatchling morphology measurements were used to quantify the overall body size and yearly morphological variation of leatherback hatchlings at SPNWR (Table S1; Objective 1). We used Bartlett's test and found that our morphometric data did not meet the assumption of homogeneity of variance. We graphically evaluated our morphometric data using QQnormal plots and found that our data did meet assumptions of normality. Therefore, we used our untransformed data in downstream analyses. We evaluated whether there were differences in hatchling mass, SCL, SCW, BD, and BCI between years by performing ANOVAs. We calculated effect size with the R package 'sjstats' v.0.14.3 (Lüdecke 2018). We also performed principal component analysis (PCA) to visualize differences in hatchling mass, SCL, SCW, $\mathrm{BD}$, and $\mathrm{BCI}$ by year and to evaluate annual morphological variation with a statistical method that is not hypothesis-based.

We evaluated differences in mass, $\mathrm{SCL}, \mathrm{SCW}, \mathrm{BD}$, and $\mathrm{BCI}$ based on paternal identity between individuals within each clutch that exhibited multiple paternity and had paired genetic and morphological data (Table S1, Objective 2). We did this by calculating pairwise differences for each morphological measurement and comparing the mean differences between full-siblings ( $\mathrm{n}=143$ comparisons) to the mean differences between half-siblings $(\mathrm{n}=165$ comparisons) with 1-tailed $t$-tests to determine whether there were greater differences between half-siblings.

We used hatchling morphological measurements from both multiple and single paternity clutches to assess whether multiple paternity increased withinclutch morphological variation (Table S1, Objective $3)$. We calculated the variances in mass, SCL, SCW, $\mathrm{BD}$, and $\mathrm{BCI}$ for each clutch and performed 1-tailed $t$-tests to determine if mean within-clutch variances of each morphological value were greater in the 10 clutches with multiple paternity than in the 17 single paternity clutches ( $\mathrm{n}=10$ to 24 hatchlings clutch ${ }^{-1}$ ).

We applied a Bonferroni correction for all analyses $(\alpha=0.01)$ to account for multiple hypothesis tests (Rice 1989). All analyses were conducted in R v.3.4.4 (R Core Team 2018).

\section{RESULTS}

\subsection{Morphological variation over time (Objective 1)}

We measured 2617 hatchlings from 199 clutches, with an average of 13 hatchlings clutch ${ }^{-1}$. Hatchlings at SPNWR had a mean $( \pm$ SD) mass of $45.2 \pm 3.4 \mathrm{~g}$, an SCL of $59.2 \pm 2.4 \mathrm{~mm}$, an SCW of $39.7 \pm 2.2 \mathrm{~mm}$, a BD of $25.2 \pm 1.4 \mathrm{~mm}$, and a BCI of $2.19 \pm 0.24\left(\mathrm{~g} \mathrm{~mm}^{-3} \times\right.$ 10000) (Fig. 2).

Among years, there were significant differences in hatchling mass, SCW, BD, and BCI (Table 1, Fig. 3). There was no significant difference in mean SCL grouped by year $\left(\right.$ ANOVA, $F_{3,2610}=3.47, \mathrm{p}=0.015$; Fig. 3). However, the effect sizes of the significant differences in morphological measurements between years were small (Table 1, Fig. 3). The first PCA axis for the 5 morphological values explained $45.1 \%$ of the covariation in body size (Fig. S1). The PCA showed that hatchlings did cluster by year but that the clusters overlapped greatly in PC space. The loadings of the first 2 principal components are shown in Table S2.

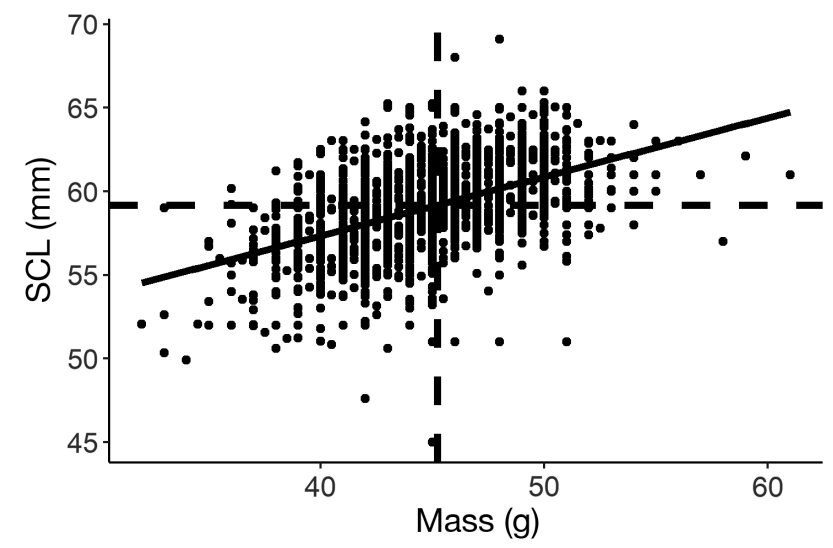

Fig. 2. Body size (straight carapace length [SCL] versus mass) of leatherback turtle hatchlings at Sandy Point National Wildlife Refuge from 2009, 2012, 2013, and 2016; $\mathrm{n}=2617$ from 199 clutches. Each point represents 1 hatchling. Dashed lines: mean mass $(45.2 \mathrm{~g})$ and mean SCL (59.2 mm); solid line: line of best fit (adjusted $\mathrm{r}^{2}=0.26, \mathrm{p}<0.001$ ) 
Table 1. ANOVA results examining differences in leatherback turtle mass, straight carapace length (SCL), straight carapace width (SCW), body depth (BD), and body condition index (BCI) among years. Statistically significant $p$-values $(\alpha=0.01$ after Bonferroni correction) are in bold

\begin{tabular}{|lrcrr|}
\hline $\begin{array}{l}\text { Morpho- } \\
\text { metric }\end{array}$ & F-statistic & df & p-value & $\begin{array}{c}\text { Effect } \\
\text { size }\end{array}$ \\
\hline Mass & 37.21 & 3,2610 & $\mathbf{< 0 . 0 0 1}$ & 0.041 \\
SCL & 3.47 & 3,2610 & 0.015 & 0.004 \\
SCW & 54.77 & 3,2586 & $\mathbf{< 0 . 0 0 1}$ & 0.060 \\
BD & 318.20 & 3,2581 & $\mathbf{< 0 . 0 0 1}$ & 0.270 \\
BCI & 37.50 & 3,2607 & $<\mathbf{0 . 0 0 1}$ & 0.041 \\
\hline
\end{tabular}

\subsection{Paternal identity and morphological variation (Objective 2)}

The microsatellite markers that we used were polymorphic in the population of nesting females at SPNWR; summary statistics for the nesting females may be found in Table 2. Allelic richness ranged from 10 to 15 alleles, the probability of unrelated individuals sharing a genotype was $Q=8.81 \times 10^{-7}$ (Hanotte et al. 1991), and the probability of detecting multiple paternity in this population was $D=0.993$ (Westneat et al. 1987). We found low frequencies of null alleles in all loci, and the genotyping error rates ranged from 0.06 to $3.0 \%$ (Table 2). Single locus genotype errors were either corrected upon further examination or excluded from further analysis.

We generated genotypes for 12 to 24 hatchlings clutch $^{-1}$ from 27 clutches $(\mathrm{n}=371$ hatchlings genotyped). We used 7 to 24 hatchlings clutch ${ }^{-1}$ in the multiple paternity analysis. We considered 2 or more paternal genotypes given by GERUD 1.0 that differed at 2 or more loci as evidence of multiple paternity. We found 3 clutches with multiple paternity from 2012 and 2 clutches with multiple paternity

Fig. 3. Leatherback turtle hatchling morphological measurements grouped by year: (A) mass, (B) straight carapace length (SCL), (C) straight carapace width (SCW), (D) body depth (BD), and (E) body condition index (BCI). Boxplot parameters: line: median; notch: $95 \%$ confidence interval of the median; labelled points: mean; box: first and third quartiles; whiskers: 1.5 times the interquartile range; points: values outside 1.5 times the interquartile range. Boxes representing yearly means with the same lowercase letters (a-d) above are not statistically different; boxes with different letters above are statistically different (Tukey's test, $\mathrm{p}<$ 0.05). There were small but significant differences between years for all morphological measurements except SCL

(ANOVA, $\mathrm{p}<0.01$ )
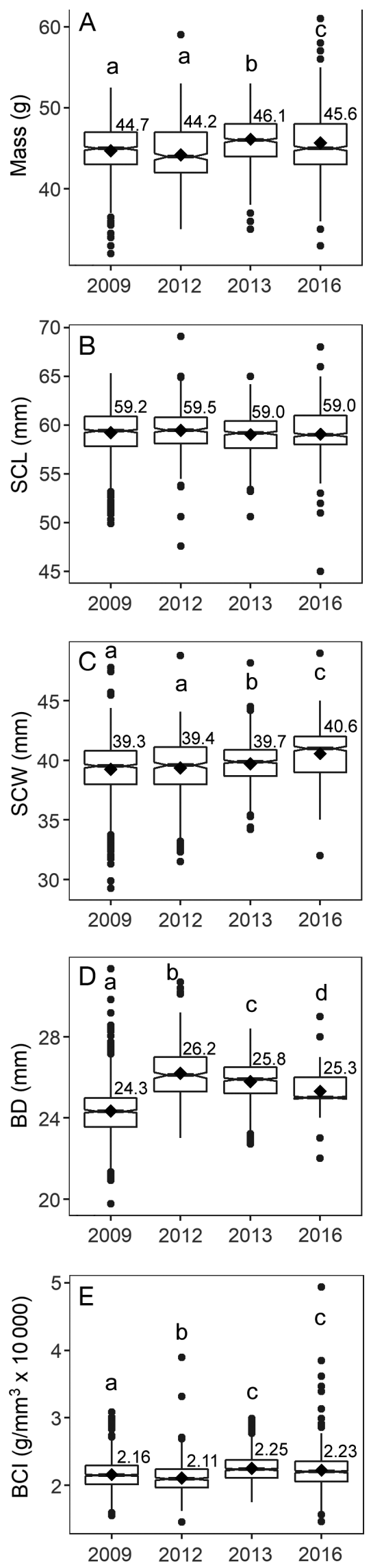
Table 2. Characteristics of the 4 polymorphic microsatellite markers calculated from genotypes of 30 nesting leatherback turtle females. NA: number of alleles; $H_{\mathrm{e}}$ : expected heterozygosity; $H_{\mathrm{o}}$ : observed heterozygosity; $\mathrm{p}$ : $\mathrm{p}$-value generated using a chi-squared test for Hardy-Weinberg (HW) equilibrium; q: probability of 2 unrelated individuals sharing a genotype at each locus; $d$ : probability of detecting multiple paternity at each locus; fn: frequency of null alleles

\begin{tabular}{|lccccccccr|}
\hline Locus & $\begin{array}{c}\text { Range } \\
\text { (bp) }\end{array}$ & NA & $H_{\mathrm{e}}$ & $H_{\mathrm{o}}$ & $\begin{array}{c}\mathrm{p} \\
\text { (HW) }\end{array}$ & $q$ & $d \begin{array}{c}\text { Geno- } \\
\text { typing error } \\
\text { rate (\%) }\end{array}$ & fn \\
\hline DERM01 & $215-263$ & 11 & 0.89 & 0.83 & 0.17 & 0.03 & 0.75 & 2.959 & 0.026 \\
DERM02 & $166-222$ & 15 & 0.88 & 0.96 & 0.34 & 0.03 & 0.74 & 1.835 & -0.054 \\
DERM37 & $145-199$ & 13 & 0.88 & 0.81 & 0.54 & 0.03 & 0.74 & 2.961 & 0.031 \\
DERM48 & $338-374$ & 10 & 0.83 & 0.93 & 0.47 & 0.04 & 0.63 & 0.573 & -0.069 \\
\hline
\end{tabular}

in body size than hatchlings from the same mother but different fathers.

\subsection{Multiple paternity and within-clutch morphological variation (Objective 3)}

We used multiple and single paternity clutches from the analysis above as well as 5 multiple paternity clutches and 5 single paternity clutches from Stewart \& Dutton (2011) to assess the relationship between the number of contributing fathers and within-clutch morphological variation. We calcu-

from 2015; the remainder of the clutches were single paternity. We identified 32 males that mated and successfully produced offspring with 26 females in 3 different nesting seasons. The probability of unrelated male individuals sharing a genotype was $Q=8.81 \times$ $10^{-7}$ (Hanotte et al. 1991), and thus we are confident that there were at least 32 distinct breeding males identified with fully resolved genotypes during the 3 nesting seasons.

For the 5 clutches with multiple paternity and paired morphological measurements, we assigned each hatchling to a father based on its paternal alleles. There were no significant relationships between paternal identity and 5 morphological measurements in leatherback hatchlings. We found no significant differences among mass, SCL, SCW, BD, or BCI when comparing differences in morphological measurements between full-siblings ( $\mathrm{n}=143$ comparisons) and half-siblings ( $\mathrm{n}=165$ comparisons) in 5 clutches with multiple paternity from 2012 and 2015 (Table 3, Fig. 4). Simply put, hatchlings from the same mother and father were not closer to each other

Table 3. Statistics from $t$-tests of differences in leatherback turtle mass, straight carapace length (SCL), straight carapace width (SCW), body depth (BD), and body condition index (BCI) between full-siblings ( $\mathrm{n}=143$ comparisons) and half-siblings ( $\mathrm{n}=165$ comparisons) in 5 clutches with multiple paternity. There were no significant differences $(\alpha=0.01$ after Bonferroni correction)

\begin{tabular}{|lrcc|}
\hline Morphometric & $t$-value & df & $p$-value \\
\hline Mass & -0.57 & 302.6 & 0.715 \\
SCL & -0.37 & 305.4 & 0.644 \\
SCW & 0.01 & 305.7 & 0.496 \\
BD & -1.79 & 304.4 & 0.963 \\
BCI & 0.88 & 301.2 & 0.189 \\
\hline
\end{tabular}

lated the variances in mass, SCL, SCW, BD, and BCI of 10 clutches with multiple paternity and 17 clutches with single paternity (Table S3). Multiple paternity clutches did not have significantly greater variances than single paternity clutches for mass, SCL, SCW, BD, or BCI (Table 4).

\section{DISCUSSION}

In this study, we characterized the variation in leatherback hatchling morphology at SPNWR, St. Croix, US Virgin Islands and established a baseline of hatchling morphometrics for future studies. We found no evidence that paternal identity is linked to differences in hatchling body size within the same clutch. We also demonstrated the use of reconstructed paternal genotypes to assign hatchlings to a father. This technique is useful as it allows researchers to assess the quantity and quality of males' offspring without direct observation of mating. To date, there have been few published studies to apply multiple paternity analysis in this way (Lee \& Hays 2004, Stewart \& Dutton 2014, Alfaro-Núñez et al. 2015, Howe et al. 2018).

The hatchlings from SPNWR were $5.1 \mathrm{~g}$ heavier $(45.2 \pm 3.4$ vs. $40.1 \pm 2.7 \mathrm{~g}), 2.3 \mathrm{~mm}$ longer (SCL; 59.2 \pm 2.4 vs. $56.9 \pm 2.1 \mathrm{~mm}$ ), and $0.9 \mathrm{~mm}$ wider (SCW; $39.7 \pm 2.2$ vs. $38.8 \pm 1.8 \mathrm{~mm}$ ) than hatchlings in the Pacific Costa Rican population from Parque Las Baulas from 2001 to 2004 (Wallace et al. 2007). There were similar differences in size found between nesting females in the Caribbean (curved carapace length [CCL] > $150 \mathrm{~cm}$ ) and in the East Pacific (CCL $<150 \mathrm{~cm}$ ) (Stewart et al. 2007, Robinson et al. 2017). These results are consistent with previous findings that Northwest Atlantic leatherbacks tend to be 

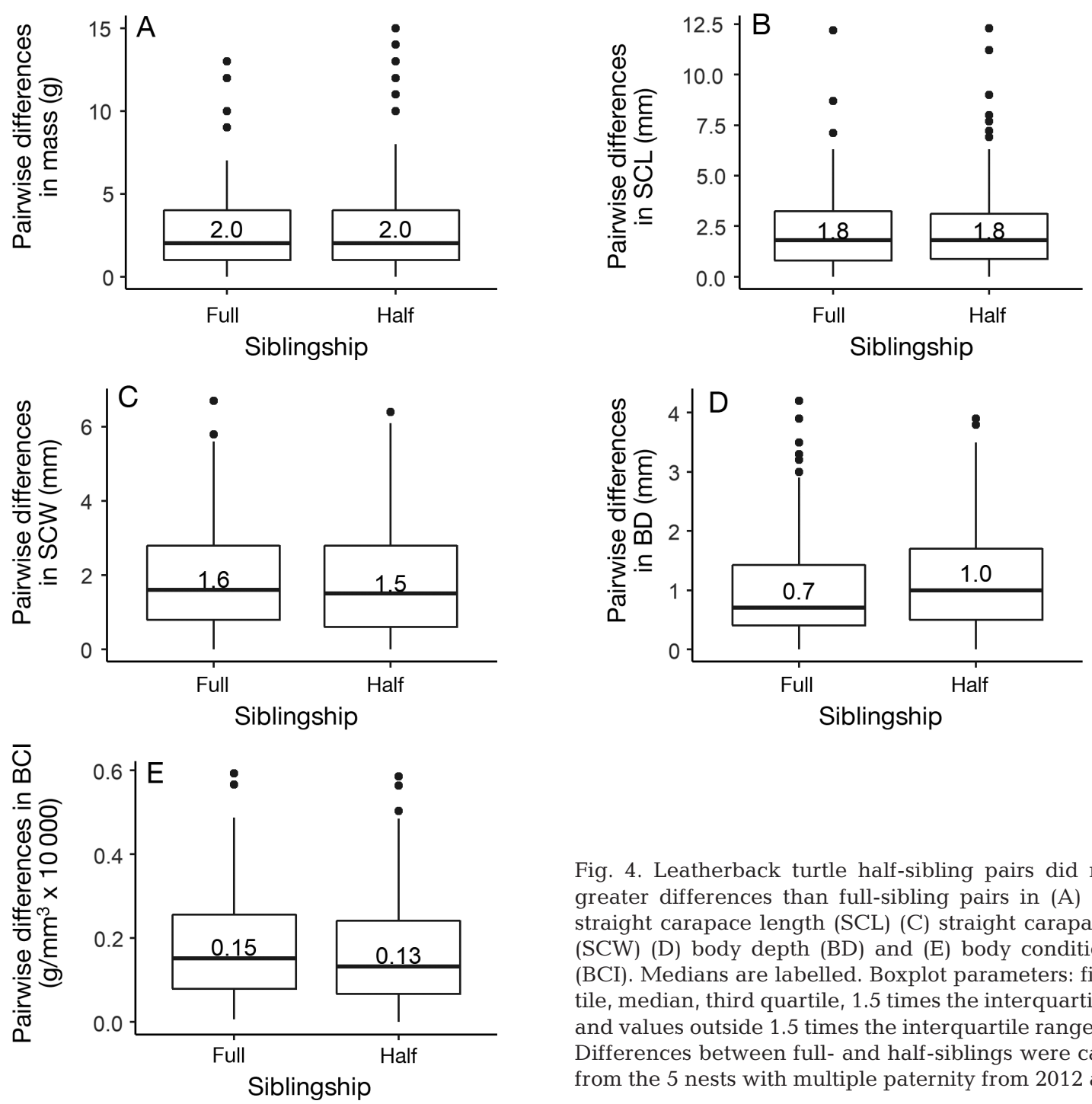

Fig. 4. Leatherback turtle half-sibling pairs did not have greater differences than full-sibling pairs in (A) mass (B) straight carapace length (SCL) (C) straight carapace width (SCW) (D) body depth (BD) and (E) body condition index (BCI). Medians are labelled. Boxplot parameters: first quartile, median, third quartile, 1.5 times the interquartile range, and values outside 1.5 times the interquartile range (points). Differences between full- and half-siblings were calculated from the 5 nests with multiple paternity from 2012 and 2015

larger than East Pacific leatherbacks. We also documented changes in hatchling morphology measurements over multiple years. The largest differences between yearly means were $1.9 \mathrm{~g}$ (mass; 2012 and 2013), $0.5 \mathrm{~mm}$ (SCL; 2012 and 2013), $1.3 \mathrm{~mm}$ (SCW;

2009 and 2016), $1.9 \mathrm{~mm} \mathrm{(BD;} 2009$ and 2012), and $0.14\left(\mathrm{~g} \mathrm{~mm}^{-3} \times 10000\right)\left(\mathrm{BCI}_{i} 2012\right.$ and 2013), and the effect sizes for each morphological measurement were small. The results of the PCA were similarly ambiguous in that there was visually detectable clus-

Table 4. Mean within-clutch variances of leatherback turtle mass, straight carapace length (SCL), straight carapace width (SCW), body depth (BD), and body condition index (BCI) and statistics from 1-tailed $t$-tests to determine if the mean withinclutch variances of each morphometric were greater in the 10 clutches with multiple paternity (MP) than in the 17 single paternity (SP) clutches ( $\mathrm{n}=10$ to 24 hatchlings lutch $^{-1}$ ). There were no significant differences $(\alpha=0.01$ after Bonferroni correction)

\begin{tabular}{|lccrrr|}
\hline Morphometric & Mean variance of MP clutches & Mean variance of SP clutches & $t$-value & df & $\mathrm{p}$-value \\
\hline Mass & $5.02 \mathrm{~g}^{2}$ & $3.33 \mathrm{~g}^{2}$ & 0.87 & 9.77 \\
SCL & $3.70 \mathrm{~mm}^{2}$ & $3.69 \mathrm{~mm}^{2}$ & 0.004 & 16.50 & 0.202 \\
SCW & $2.42 \mathrm{~mm}^{2}$ & $2.11 \mathrm{~mm}^{2}$ & 0.73 & 19.04 & 0.237 \\
BD & $0.83 \mathrm{~mm}^{2}$ & $0.70 \mathrm{~mm}^{2}$ & 0.84 & 16.15 & 0.208 \\
BCI & $0.03\left(\mathrm{~g} \mathrm{~mm}^{-3} \times 10000\right)^{2}$ & $0.05\left(\mathrm{~g} \mathrm{~mm}^{-3} \times 10000\right)^{2}$ & -1.61 & 19.82 \\
\hline
\end{tabular}


tering by year, indicating that there is yearly variation in hatchling body size, but the clusters had substantial overlap in PC space, indicating that the differences between years are small. The overall variation between years was small and may not be biologically significant. However, there were statistically significant differences among years for all measurements except SCL. The differences among years suggest there are non-genetic drivers of morphological variation. Previous studies have shown that hatchling morphometrics fluctuate with environmental conditions such as temperature and moisture (McGehee 1990, Booth \& Astill 2001). While we did not measure nest temperature or moisture, future studies could consider testing these factors as drivers of morphological variation in hatchlings. There are a variety of different factors that may affect annual variation in hatchling morphology at SPNWR. Beach erosion in this area is highly variable, which may affect sand moisture in nests, especially near the high-water line. Hatchling morphology may be influenced by a combination of environmental factors, maternal investment, and genetics, which may include paternal contribution (Janzen 1993, Bobyn \& Brooks 1994, Booth \& Astill 2001, Finkler 2006, Wallace at al. 2006, 2007).

While we did not find a direct effect of paternal identity on leatherback hatchling morphological measurements, there may still be some genetic component to hatchling morphology contributed by the father. This has been demonstrated in other species such as wandering albatross chicks, where larger fathers produce larger chicks (Cornioley et al. 2017); however, in that study they were able to measure the males, while we were not. If paternal identity affected hatchling body size within a clutch, we would expect half-siblings to have greater pairwise differences in morphological measurements than fullsiblings. Although our sample size for the paternal analysis was small and hatchling morphology may not be a strong indicator of male contribution in sea turtles, we did not find greater differences in morphological measurements between half-siblings. Future paternal contribution studies could investigate relationships between paternal identity and other potential measures of fitness to assess offspring quality. For example, several studies have found relationships between hatchling locomotor performance and incubation temperature, and suggest locomotor performance as a potential measure of fitness (Maulany et al. 2012, Booth et al. 2013, Sim et al. 2015, Booth 2017).

Our comparison of within-clutch morphological variation between multiple and single paternity clut- ches supports the idea that multiple paternity may not be beneficial to female turtles or their offspring. Similarly, Howe et al. (2018) found that multiple paternity did not significantly influence loggerhead turtle hatchling size or within-clutch size variation. Previous studies on frogs (Crinia georgiana; Byrne \& Roberts 2000) and wild house mice (Mus musculus; Thonhauser et al. 2014) also found that multiple paternity did not increase variation in offspring size. While we may expect that increasing genetic variation enables increased phenotypic variation via potentially novel combinations of alleles, this may not be reflected in hatchling body size. It is possible that body size at hatching is not a strongly heritable trait in leatherbacks, as adults have indeterminate growth (Berry \& Shine 1980). Phillips et al. (2017) found that paternal genetic traits may affect hatching success in hawksbill turtle clutches, though the authors stressed that it is not clear how females could exploit this effect. However, Lee \& Hays (2004) and Wright et al. (2013) found that green turtle females that mated with multiple males did not have greater reproductive success than females that mated with a single male, demonstrating no clear benefit to multiple paternity in those instances (Lee \& Hays 2004, Wright et al. 2013). A recent review of multiple paternity in marine turtles found that polyandry generally does not increase offspring quality, and that females likely mate with multiple males not because it is beneficial, but because it is costly to avoid doing so (Lee et al. 2018). In fact, there has been little evidence for widespread direct or indirect fitness advantages from multiple paternity across taxa, especially in wild populations for which breeding cannot be manipulated (Uller \& Olsson 2008). While hatchling body size may not be a true indicator of hatchling fitness, our findings demonstrate no clear difference between offspring from clutches with single and those with multiple paternity, and indicate that increasing genetic variation in offspring does not directly affect offspring size.

Female turtle reproductive success is often measured by the quantity of eggs laid, quantity of hatchlings that emerged, or by hatching success rate (Wallace et al. 2006), which is possible because biologists can confirm the maternal identity associated with a clutch via PIT tags, flipper tags, or genetic identity. However, paternity of turtle hatchlings is difficult to measure, as are potential relationships between hatchling fitness and paternity. We demonstrated that multiple paternity analyses may be used to assess the quantity and quality of a male's offspring without the need to observe cryptic mating events. This informa- 
tion contributes to our understanding about paternal contribution to potential measures of hatchling fitness. This technique can be combined with other techniques such as acoustic telemetry (Thums et al. 2016) to further investigate relationships between paternal identity and hatchling fitness.

In addition, the genotypes generated by multiple paternity studies contribute to an understanding of potential mating patterns, such as relative paternal contribution to each clutch and the breeding sex ratios of leatherback populations. We identified 32 males that were active in the breeding population (mating with 26 females) during 3 yr. While we only identified a few of the males that successfully mated from a small proportion of the females that nested in each year, our preliminary data showed annual variation in male to female breeding sex ratios. We found the lowest rate of multiple paternity ( 0 out of 10 ) in 2016, which may reflect the low number of females that nested that year (K. R. Stewart unpubl. data). Jensen et al. (2006) showed that rates of multiple paternity in olive ridley turtles were lower when nesting population density was lower, and Lee et al. (2018) found that the incidence of multiple paternity across rookeries of multiple marine turtle species was tightly correlated with 'packing density.'

We have shown that it is possible to confidently assign hatchlings to a father, which can allow researchers to assess male reproductive success (quantity and quality of offspring) and to compare characteristics of their offspring. Reproductive success data have been recorded for nesting females for decades, and moving forward, multiple paternity analysis may allow us to track reproductive output of individual males over space and time as well. Understanding male contribution to offspring quality and quantity is especially important as warming environmental temperatures threaten to feminize sea turtle populations (Jensen et al. 2018). Using multiple paternity analysis to reconstruct male genotypes may help increase our understanding of the behavior and biology of cryptic male leatherbacks.

\section{CONCLUSIONS}

The results of this study indicate that paternal identity does not have a direct effect on leatherback hatchling morphology, as we found no significant differences in body size between leatherback sea turtle hatchlings from 2 different fathers but the same mother. Additionally, multiple paternity did not have a clear impact on the variations for within-clutch hatchling morphometrics. While a paternal genetic component to hatchling size may still exist, we were unable to detect a relationship, possibly due to our small sample size of multiple paternity clutches. We did, however, find yearly variation in hatchling morphology. Based on the findings of this study, further research into genetic and environmental factors that affect hatchling body size, and other measures of hatchling quality, would provide insight into conditions affecting endangered leatherback sea turtle populations.

Acknowledgements. We thank Morgane Lauf, Amy Lanci, Victoria Pease, and staff and volunteers of the Marine Mammal and Turtle Division for their invaluable guidance and support with laboratory and fieldwork. Thank you to Dr. Peter Dutton and Dr. Karl Phillips for providing comments which greatly improved the manuscript. Thank you to members of the Kurle Lab at the University of California, San Diego for advice on statistical analysis and figures. We are sincerely grateful to Mike Evans and Claudia Lombard from US Fish and Wildlife (St. Croix) for sharing their knowledge; and to the 2015 (Rachel Arney, Romina Ramos, Amanda Kiernan, Caitlin Lanphear, Matt Rutledge, Mollie Atler, and Jen Valiulis) and 2016 (Gabby Carvajal, Dana DeSousa, Shannon Borowy, Emlyn Crocker, Sarah Biesemier, Sarah DeLand, and Jeremy Smith) SPNWR Leatherback Project field staff, the Marine Turtle Genetics Program, and many volunteers for their dedicated work in the field. All 2012 and 2013 hatchling morphometrics were provided by Shane Morales. Thank you to Nina Mauney for providing a map of SPNWR. Lastly, thank you to Christina MacMillan, Claire Gonzales, Romina Ramos, Drue Frey, and others for patiently recording morphological measurements with S.M.B. Laboratory work was performed at Southwest Fisheries Science Center, National Marine Fisheries Service (NMFS), La Jolla, CA. This work was supported in part by The Ocean Foundation, The National Save the Sea Turtle Foundation, Ocean Planet Research, by Southwest Fisheries Science Center, NMFS, and by the University of California, San Diego. All procedures for collecting morphometrics and genetic samples from leatherback hatchlings were rigorously reviewed and approved under US Fish and Wildlife Service Special Use Permits (nos. 41526-2009-004, 41526-2009-006, 415262012-002, 41526-2013-002，41526-FY2015-006) or by the Department of Planning and Natural Resources of the US Virgin Islands (nos. STX-032-09, STX-016-12, STX034-13, DFW15037X, and DFW16030X). Procedures were also reviewed and approved by the NMFS Southwest/Pacific Islands Science Centers Animal Care and Use Committee (IACUC no. SWPI-2016-02). No hatchlings were euthanized or sacrificed, and no hatchlings were given anesthesia during any part of our studies.

\section{LITERATURE CITED}

Adamack AT, Gruber B (2014) PopGenReport: simplifying basic population genetic analyses in R. Methods Ecol Evol 5:384-387

Alfaro-Núñez A, Jensen MP, Abreu-Grobois FA (2015) Does 
polyandry really pay off? The effects of multiple mating and number of fathers on morphological traits and survival in clutches of nesting green turtles at Tortuguero. PeerJ 3:e880

*Alstad T, Shamblin BM, Bagley D, Ehrhart LM, Nairn CJ (2011) Isolation and characterization of tetranucleotide microsatellites from the leatherback turtle (Dermochelys coriacea). Conserv Genet Resour 3:457-460

Berry JF, Shine R (1980) Sexual size dimorphism and sexual selection in turtles (Order Testudines). Oecologia 44: 185-191

Bjorndal KA, Bolten AB (2000) Green turtle somatic growth model: evidence for density dependence. Ecol Appl 10: 269-282

* Bobyn ML, Brooks RJ (1994) Interclutch and interpopulation variation in the effects of incubation conditions on sex, survival and growth of hatchling turtles (Chelydra serpentina). J Zool (Lond) 233:233-257

Booth DT (2017) The influence of incubation temperature on sea turtle hatchling quality. Integr Zool 12:352-360

Booth DT, Astill K (2001) Incubation temperature, energy expenditure and hatchling size in the green turtle (Chelonia mydas), a species with temperature-sensitive sex determination. Aust J Zool 49:389-396

* Booth DT, Feeney R, Shibata Y (2013) Nest and maternal origin can influence morphology and locomotor performance of hatchling green turtles (Chelonia mydas) incubated in field nests. Mar Biol 160:127-137

Byrne PG, Roberts JD (2000) Does multiple paternity improve fitness of the frog Crinia georgiana? Evolution 54: 968-973

Carr T, Carr N (1986) Dermochelys coriacea (leatherback sea turtle) copulation. Herpetol Rev 17:24-25

* Chakraborty R, Zhong Y, Jin L, Budowle B (1994) Nondetectability of restriction fragments and independence of DNA fragment sizes within and between loci in RFLP typing of DNA. Am J Hum Genet 55:391-401

Chassin-Noria O, Macip-Ríos R, Dutton PH, Oyama K (2017) Multiple paternity in the East Pacific green turtle (Chelonia mydas) from the Pacific coast of Mexico. J Exp Mar Biol Ecol 495:43-47

* Cornioley T, Jenouvrier S, Börger L, Weimerskirch H, Ozgul A (2017) Fathers matter: male body mass affects life-history traits in a size-dimorphic seabird. Proc R Soc B 284: 20170397

* Crim JL, Spotila D, Spotila R, O'Connor M and others (2002) The leatherback turtle, Dermochelys coriacea, exhibits both polyandry and polygyny. Mol Ecol 11:2097-2106

Duran N, Dunbar SG, Escobar RA, Standish TG (2015) High frequency of multiple paternity in a solitary population of olive ridley sea turtles in Honduras. J Exp Mar Biol Ecol 463:63-71

Dutton PH, Stewart KR (2013) A method for sampling hatchling sea turtles for the development of a genetic tag. Mar Turtle Newsl 138:3-7

* Dutton PH, Bowen BW, Owens DW, Barragan A, Davis SK (1999) Global phylogeography of the leatherback turtle (Dermochelys coriacea). J Zool (Lond) 248:397-409

*Dutton DL, Dutton PH, Chaloupka M, Boulon RH (2005) Increase of a Caribbean leatherback turtle Dermochelys coriacea nesting population linked to long-term nest protection. Biol Conserv 126:186-194

Finkler MS (2006) Does variation in soil water content induce variation in the size of hatchling snapping turtles (Chelydra serpentina)? Copeia 2006:769-777
Frey A, Dutton PH, Shaver DJ, Walker JS, Rubio C (2014) Kemp's ridley Lepidochelys kempii nesting abundance in Texas, USA: a novel approach using genetics to improve population census. Endang Species Res 23:63-71

Garner JA, MacKenzie DS, Gatlin D (2017) Reproductive biology of Atlantic leatherback sea turtles at Sandy Point, St. Croix: the first 30 years. Chelonian Conserv Biol 16:29-43

*González-Garza BI, Stow A, Sánchez-Teyer LF, ZapataPérez O (2015) Genetic variation, multiple paternity, and measures of reproductive success in the critically endangered hawksbill turtle (Eretmochelys imbricata). Ecol Evol 5:5758-5769

*Hanotte O, Burke T, Armour JAL, Jeffreyst JA (1991) Hypervariable minisatellite DNA sequences in the Indian peafowl Pave cristatus. Genomics 9:587-597

* Hillis DM, Davis SK (1986) Evolution of ribosomal DNA: fifty million years of recorded history in the frog genus Rana. Evolution 40:1275-1288

* Howe M, FitzSimmons NN, Limpus CJ, Clegg SM (2018) Multiple paternity in a Pacific marine turtle population: maternal attributes, offspring outcomes and demographic inferences. Mar Biol 165:2

* Ireland JS, Broderick AC, Glen F, Godley BJ and others (2003) Multiple paternity assessed using microsatellite markers, in green turtles Chelonia mydas (Linnaeus, 1758) of Ascension Island, South Atlantic. J Exp Mar Biol Ecol 291:149-160

James MC, Eckert SA, Myers RA (2005) Migratory and reproductive movements of male leatherback turtles (Dermochelys coriacea). Mar Biol 147:845-853

* Janzen FJ (1993) The influence of incubation temperature and family on eggs, embryos, and hatchlings of the smooth softshell turtle (Apalone mutica). Physiol Zool 66: 349-373

Janzen FJ, Tucker JK, Paukstis GL (2000) Experimental analysis of an early life-history stage: avian predation selects for larger body size of hatchling turtles. J Evol Biol 13:947-954

Janzen FJ, Tucker JK, Paukstis GL (2007) Experimental analysis of an early life-history stage: Direct or indirect selection on body size of hatchling turtles? Funct Ecol 21: 162-170

Jensen MP, Abreu-Grobois FA, Frydenberg J, Loeschcke V (2006) Microsatellites provide insight into contrasting mating patterns in arribada vs. non-arribada olive ridley sea turtle rookeries. Mol Ecol 15:2567-2575

Jensen MP, Allen CD, Eguchi T, Bell IP and others (2018) Environmental warming and feminization of one of the largest sea turtle populations in the world. Curr Biol 28: $154-159$

Jones AG (2001) GERUD1.0: a computer program for the reconstruction of parental genotypes from progeny arrays using multilocus DNA data. Mol Ecol 1:215-218

Joseph J, Chong J, Shaw PW (2017) Multiple paternity in egg clutches of green turtles in Redang Island and Sabah Turtle Island Park, Malaysia. J Sustain Sci Manag 12: 12-22

Kempenaers B, Verheyen GR, Dhondt AA (1997) Extrapair paternity in the blue tit (Parus caeruleus): female choice, male characteristics, and offspring quality. Behav Ecol 8: 481-492

Kichler K, Holder MT, Davis SK, Marquez R, Owens DW (1999) Detection of multiple paternity in the Kemp's ridley sea turtle with limited sampling. Mol Ecol 8:819-830 
Komoroske LM, Jensen MP, Stewart KR, Shamblin BM, Dutton PH (2017) Advances in the application of genetics in marine turtle biology and conservation. Front Mar Sci 4: 156

Labrada-Martagon V, Mendez-Rodriguez LC, Gardner SC, Lopez-Castro M, Zenteno-Savin T (2010) Health indices of the green turtle (Chelonia mydas) along the Pacific coast of Baja California Sur, Mexico. I. Blood biochemistry values. Chelonian Conserv Biol 9:173-183

Lee PLM (2008) Molecular ecology of marine turtles: new approaches and future directions. J Exp Mar Biol Ecol 356:25-42

Lee PLM, Hays GC (2004) Polyandry in a marine turtle: females make the best of a bad job. Proc Natl Acad Sci USA 101:6530-6535

Lee PLM, Schofield G, Haughey RI, Mazaris AD, Hays GC (2018) A review of patterns of multiple paternity across sea turtle rookeries. Adv Mar Biol 79:1-31

Lüdecke D (2018) sjstats: statistical functions for regression models. $\mathrm{R}$ package version 0.14.3

Maulany RI, Booth DT, Baxter GS (2012) The effect of incubation temperature on hatchling quality in the olive ridley turtle, Lepidochelys olivacea, from Alas Purwo National Park, East Java, Indonesia: implications for hatchery management. Mar Biol 159:2651-2661

McDonald DL, Dutton PH (1996) Use of PIT tags and photo identification to revise remigration estimates of leatherback turtles (Dermochelys coriacea) nesting in St. Croix, US Virgin Islands, 1979-1995. Chelonian Conserv Biol 2: 148-152

McGehee MA (1990) Effects of moisture on eggs and hatchlings of loggerhead sea turtles (Caretta caretta). Herpetologica 46:251-258

McMahon CR, Burton HR, Bester MN (2000) Weaning mass and the future survival of juvenile southern elephant seals, Mirounga leonina, at Macquarie Island. Antarct Sci 12:149-153

Moore MK, Ball RMJ (2002) Multiple paternity in loggerhead turtle (Caretta caretta) nests on Melbourne Beach, Florida: a microsatellite analysis. Mol Ecol 11:281-288

" Pearse DE, Avise JC (2001) Turtle mating systems: behavior, sperm storage, and genetic paternity. J Hered 92: 206-211

Pearse DE, Janzen FJ, Avise JC (2002) Multiple paternity, sperm storage, and reproductive success of female and male painted turtles (Chrysemys picta) in nature. Behav Ecol Sociobiol 51:164-171

Phillips KP, Jorgensen TH, Jolliffe KG, Jolliffe S (2013) Reconstructing paternal genotypes to infer patterns of sperm storage and sexual selection in the hawksbill turtle. Mol Ecol 22:2301-2312

Phillips KP, Jorgensen TH, Jolliffe KG, Richardson DS (2017) Evidence of opposing fitness effects of parental heterozygosity and relatedness in a critically endangered marine turtle? J Evol Biol 30:1953-1965

R Core Team (2018) R: a language and environment for statistical computing. R Foundation for Statistical Computing, Vienna

Raymond M, Rousset F (1995) GENEPOP (version 1.2): population genetics software for exact tests and ecumenicism. J Hered 86:248-249

Rice WR (1989) Analyzing tables of statistical tests. Evolution 43:223-225

Robinson NR, Stewart KR, Dutton PH, Nel R, Paladino FV, Santidrian Tomillo P (2017) Standardising curved cara- pace length measurements for leatherback turtles, Dermochelys coriacea, to investigate global patterns in body size. Herpetol J 27:231-234

* Roden SE, Dutton PH (2011) Isolation and characterization of 14 polymorphic microsatellite loci in the leatherback turtle (Dermochelys coriacea) and cross-species amplification. Conserv Genet Resour 3:49-52

* Rousset F (2008) genepop'007: a complete re-implementation of the genepop software for Windows and Linux. Mol Ecol Resour 8:103-106

* Shamblin BM, Faircloth BC, Dodd M, Wood-Jones A and others (2007) Tetranucleotide microsatellites from the loggerhead sea turtle (Caretta caretta). Mol Ecol 7: 784-787

Sim EL, Booth DT, Limpus CJ (2015) Incubation temperature, morphology and performance in loggerhead (Caretta caretta) turtle hatchlings from Mon Repos, Queensland, Australia. Biol Open 4:685-692

Stewart KR, Dutton PH (2011) Paternal genotype reconstruction reveals multiple paternity and sex ratios in a breeding population of leatherback turtles (Dermochelys coriacea). Conserv Genet 12:1101-1113

Stewart KR, Dutton PH (2014) Breeding sex ratios in adult leatherback turtles (Dermochelys coriacea) may compensate for female-biased hatchling sex ratios. PLOS ONE 9:e88138

Stewart K, Johnson C, Godfrey MH (2007) The minimum size of leatherbacks at reproductive maturity, with a review of sizes for nesting females from the Indian, Atlantic, and Pacific Ocean basins. Herpetol J 17: 123-128

Tedeschi JNA, Mitchell NJA, Berry OC, Whiting SD, Meekan MB (2014) Reconstructed paternal genotypes reveal variable rates of multiple paternity at three rookeries of loggerhead sea turtles (Caretta caretta) in Western Australia. Aust J Zool 62:454-462

* Theissinger K, FitzSimmons NN, Limpus CJ, Parmenter CJ, Phillott AD (2009) Mating system, multiple paternity and effective population size in the endemic flatback turtle (Natator depressus) in Australia. Conserv Genet 10: 329-346

* Thonhauser KE, Thoß M, Musolf K, Klaus T, Penn DJ (2014) Multiple paternity in wild house mice (Mus musculus musculus): effects on offspring genetic diversity and body mass. Ecol Evol 4:200-209

* Thums M, Whiting SD, Reisser J, Pendoley KL and others (2016) Artificial light on water attracts turtle hatchlings during their near shore transit. R Soc Open Sci 3:160142

Uller T, Olsson M (2008) Multiple paternity in reptiles: patterns and processes. Mol Ecol 17:2566-2580

*Wallace BP, Sotherland PR, Santidrian P, Bouchard SS and others (2006) Egg components, egg size, and hatchling size in leatherback turtles. Comp Biochem Physiol A Mol Integr Physiol 145:524-532

*Wallace BP, Sotherland PR, Santidrian P, Richard T, Spotila JR, Paladino FV (2007) Maternal investment in reproduction and its consequences in leatherback turtles. Oecologia 152:37-47

Westneat DF, Frederick PC, Wiley RH (1987) The use of genetic markers to estimate the frequency of successful alternative reproductive tactics. Behav Ecol Sociobiol 21: $35-45$

Wright LI, Fuller WJ, Godley BJ, McGowan A, Tregenza T, Broderick AC (2013) No benefits of polyandry to female green turtles. Behav Ecol 24:1022-1029

Submitted: July 26, 2019; Accepted: February 12, 2020

Proofs received from author(s): April 6, 2020 